06

\title{
Дозовая зависимость формирования нанокристаллов в имплантированных гелием слоях кремния
}

\author{
(C) А.А. Ломов ${ }^{1}$, А.В. Мяконьких ${ }^{1}$, Ю.М. Чесноков ${ }^{2}$ \\ В.В. Денисов ${ }^{3,4}$, А.Н. Кириченко ${ }^{3}$, В.Н. Денисов ${ }^{3,4,5}$ \\ ${ }^{1}$ Физико-технологический институт РАН, Москва, Россия \\ ${ }^{2}$ НИЦ „Курчатовский институт“, Москва, Россия \\ ${ }^{3}$ Технологический институт сверхтвердых и новых углеродных \\ материалов, Троицк, Москва, Россия \\ ${ }^{4}$ Московский фризико-технический институт, Долгопрудный, Московская \\ обл., Россия \\ ${ }^{5}$ Институт спектроскопии РАН, Троицк, Москва, Россия \\ E-mail: lomov@ftian.ru
}

\section{Поступило в Редакцию 7 ноября 2017 г.}

Впервые доказана возможность формирования нанокристаллов в слоях кремния, подвергнутых плазменно-иммерсионной ионной имплантации гелия с энергией $5 \mathrm{keV}$. Влияние дозы имплантации на микроструктуру слоев изучено методами рентгеновской рефлектометрии, просвечивающей электронной микроскопии и комбинационного рассеяния света. Установлено, что процесс формирования кремниевых нанокристаллов с размерами $10-20 \mathrm{~nm}$ имеет ярко выраженную зависимость от потока ионов и происходит при дозе $5 \cdot 10^{17} \mathrm{~cm}^{-2}$ с последующим отжигом при $700-800^{\circ} \mathrm{C}$. Показано, что превышение этой дозы приводит к разрушению верхнего защитного субслоя и деградации оптических свойств нанокристаллов.

DOI: 10.21883/PJTF.2018.07.45883.17112

Особый интерес к исследованию нанокристаллов кремния $(n c-\mathrm{Si})$ обусловлен не только их уникальными фундаментальными свойствами и использованием в различных приложениях [1-3], но и возможностью их внедрения в планарную технологию микро- и оптоэлектроники. К сожалению, наиболее изученный и дешевый метод электрохимического анодирования [4] для формирования нанокристаллов в слоях пористого кремния не нашел широкого технологического применения 
из-за высокой поверхностной активности нанокристаллов, приводящей к деградации со временем их свойств. Попытки формирования защитных пленок на поверхности пористого кремния не дали должного результата. В настоящее время для получения защищенных нанокристаллов кремния используются различные матрицы: аморфного кремния [5], оксида и карбида кремния [6].

Одним из альтернативных методов получения нанокристаллов в приповерхностных слоях полупроводниковых подложек может быть имплантация ионов гелия или водорода. В частности, при высоких дозах имплантации этих ионов в подложках кремния могут быть сформированы внутренние пористые слои с квазисферическими полостями (пузырями и пустотами) [7]. Размеры этих полостей в кремнии зависят от технологических условий и составляют $1-30 \mathrm{~nm}$. Предполагается, что при высокой концентрации полостей их стенки могут проявлять квантово-размерные свойства. С этой целью в [8] проводилась имплантация ионов гелия с энергией $20 \mathrm{keV}$ и дозой $2.5 \cdot 10^{17} \mathrm{~cm}^{-2}$. Однако нанокристаллов кремния получено не было. Увеличение дозы внедренных ионов обычно приводит к отслаиванию верхнего субслоя, что используется в Smart-cut-технологии.

В последние годы для внедрения больших доз ионов в подложку применяется метод плазменно-иммерсионной ионной имплантации (ПИИИ). Особенностью процесса является высокая скорость имплантации и возможность облучения больших площадей. Это обстоятельство устраняет зависимость времени обработки от размера подложки и является привлекательным для использования в планарной технологии. Нами процесс ПИИИ был применен для формирования кремниевых гетероструктур, обладающих фотовольтаическими свойствами [9]. Однако доказательств формирования нанокристаллов в слоях кремния представлено не было.

Цель настоящей работы состоит в доказательстве возможности формирования нанокристаллов в слоях кремния при ПИИИ гелия и определения дозовой зависимости формирования внутренних пористых слоев с верхним защитным слоем. Исследования были проведены методами рентгеновской рефлектометрии, просвечивающей электронной микроскопии и комбинационного рассеяния света (КРС).

Внутренние пористые слои кремния были получены при $50^{\circ} \mathrm{C}$ на подложках $\mathrm{Si}(001)$, помещенных газоразрядную плазму. Имплантация ионов гелия проходила при подаче на образец прямоугольных

Письма в ЖТФ, 2018, том 44, вып. 7 


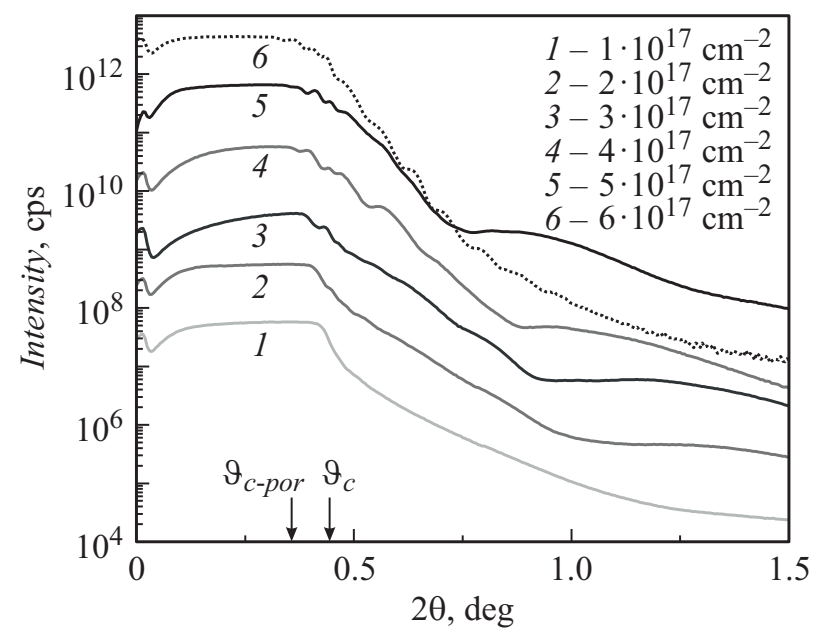

Рис. 1. Экспериментальные кривые рентгеновской рефлектометрии от подложки $\mathrm{Si}(001)$ после ПИИИ $\mathrm{He}^{+}$с энергией $5 \mathrm{keV}$. Cu-излучение. Для наглядности кривые смещены по оси ординат.

импульсов с длительностью $10 \mu \mathrm{s}$, частотой $1 \mathrm{kHz}$ и отрицательного ускоряющего потенциала $5 \mathrm{keV}$. Величина дозы внедренных ионов определялась длительностью процесса и менялась в диапазоне от $1 \cdot 10^{17}$ до $6 \cdot 10^{17} \mathrm{~cm}^{-2}$. Перед проведением плазменной обработки поверхности образцов подвергались химической очистке от естественного окисла в 5\% растворе плавиковой кислоты при комнатной температуре в течение $1 \mathrm{~min}$.

На рис. 1 представлены экспериментальные кривые рентгеновской рефлектометрии для образцов после имплантации ионов гелия с дозами $(1-6) \cdot 10^{17} \mathrm{~cm}^{-2}$. Стрелками обозначены величины критических углов полного внешнего отражения для объемного $\left(\vartheta_{c}\right)$ и пористого $\left(\vartheta_{c \text {-por }}\right)$ слоев кремния с гелиевыми пузырями.

Рассмотрим две угловые области до и после угла $\vartheta_{c}$. Анализ кривых отражения (кривые 1-6 на рис. 1) показывает, что с увеличением дозы имплантации появляются два типа интерференционных осцилляций: длиннопериодные $(L)$ и короткопериодные $(S)$, наблюдаемые в областях как до, так и после углов $\vartheta_{c}$. Осцилляции $L$ на хвостах кривых $2-5-$

Письма в ЖТФ, 2018, том 44, вып. 7 
типичные осцилляции Кизиха от тонких пленок или слоев толщиной $10-20 \mathrm{~nm}$.

В случае дозы ионов гелия $6 \cdot 10^{17} \mathrm{~cm}^{-2}$ при этих углах обнаруживаются только осцилляции $S$, соответствующие слоям толщиной 100-150 nm. Осцилляции $S$ также хорошо наблюдаются на кривых $3-5$ при углах $\vartheta_{c-p o r}<\vartheta<\vartheta_{c}$. Эти осцилляции имеют резонансную природу и в совокупности с длиннопериодными осцилляциями $L$ свидетельствуют о наличии внутри образца слоя с уменьшенной электронной плотностью. В нашем случае это пористый слой с гелиевыми пузырями, который защищен от внешней среды тонкой пленкой с достаточно резкими границами. При достижении дозы $6 \cdot 10^{17} \mathrm{~cm}^{-2}$ защитная пленка разрушается, открывая шероховатую поверхность пористого слоя. В результате это проявляется в сильном затухании рентгеновского отражения при больших углах рассеяния.

Математическая обработка экспериментальных кривых позволяет выявить характерные изменения в структуре слоев. Примеры восстановленных из рефлектометрических данных профилей $\rho(z)$ изменения электронной плотности с глубиной для этих образцов представлены в [10]. При выбранных режимах плазменной обработки вблизи поверхности образуется бислой толщиной $15 \mathrm{~nm}$, состоящий из оксида кремния $(7 \mathrm{~nm})$ и аморфного кремния $(8 \mathrm{~nm})$. Глубже расположены кристаллические пористые слои.

Для подтверждения формирования нанокристаллов в слое образец был подвергнут термическому отжигу при $\sim 800^{\circ} \mathrm{C}$. Микрофотографии пористых кристаллических слоев кремния с высоким разрешением были получены с помощью просвечивающего электронного микроскопа (ПЭМ) FEI Titan 80-300 в светлопольном режиме, образец находился в оси зоны 110.

На рис. 2 представлено изображение нанокристаллов кремния на границе пористого аморфного и пористого кристаллического слоев, полученное в режиме ПЭМ. Видно, что нанокристаллы имеют продолговатую форму (с размерами 10-20 nm) и вытянуты вдоль границы раздела. Наличия нанокристаллов с размерами менее $5 \mathrm{~nm}$ не обнаружено.

С целью определения кристаллического, нанокристаллического и аморфного состояний приповерхностных слоев и влияния дозы имплантированных ионов на формирование и размер нанокристаллов были проведены исследования методом КРС. Спектры КРС были измерены с помощью установки Renishaw in Via при возбуждении лазерным лучом 


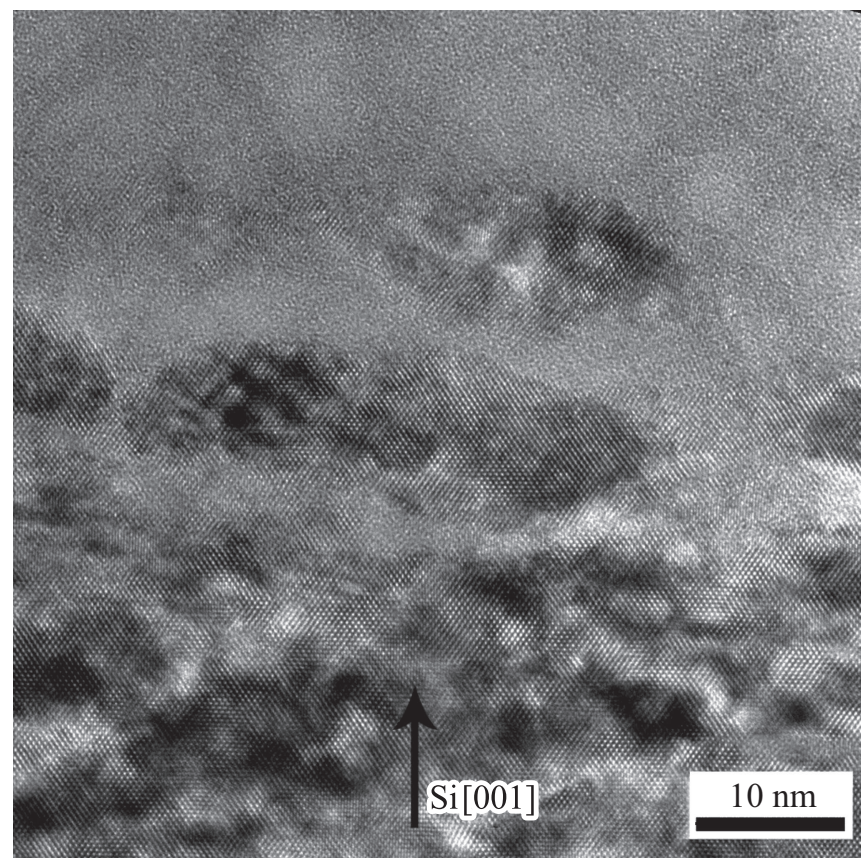

Рис. 2. ПЭМ-изображение высокого разрешения микроструктуры пористого кристаллического слоя $\mathrm{Si}(001)$ с нанокристаллами после имплантации ионов $\mathrm{He}^{+}$с энергией $5 \mathrm{keV}$ и дозой $5 \cdot 10^{17} \mathrm{~cm}^{-2}$ и термического отжига при $800^{\circ} \mathrm{C}$.

с длиной волны $532 \mathrm{~nm}$ через 100-кратный объектив, что позволило получить на образцах пятно размером $\sim 2 \mu \mathrm{m}$. Мощность лазера составляла $1 \mathrm{~mW}$ (рис. $3, a$ ) и $18 \mathrm{~mW}$ (рис. $3, b$ ). Глубина проникновения лазерного луча на длине волны $532 \mathrm{~nm}$ составляет $\sim 800 \mathrm{~nm}$.

Аморфный слой образуется на глубине $\sim 20 \mathrm{~nm}$ и закрывает пористый кристаллический слой [10], вследствие чего одновременно наблюдаются спектры кристаллического (ТО-фонон, $\sim 520 \mathrm{~cm}^{-1}$ ) и аморфного кремния. Спектры КРС аморфного кремния отражают колебательную плотность состояний с широкими полосами ТА $\left(\sim 150 \mathrm{~cm}^{-1}\right)$ и ТО $\left(\sim 480 \mathrm{~cm}^{-1}\right)$ (рис. 3 ), и их интенсивность растет линейно с увеличением дозы имплантации. Характерным признаком нанокристаллического

Письма в ЖТФ, 2018, том 44, вып. 7 

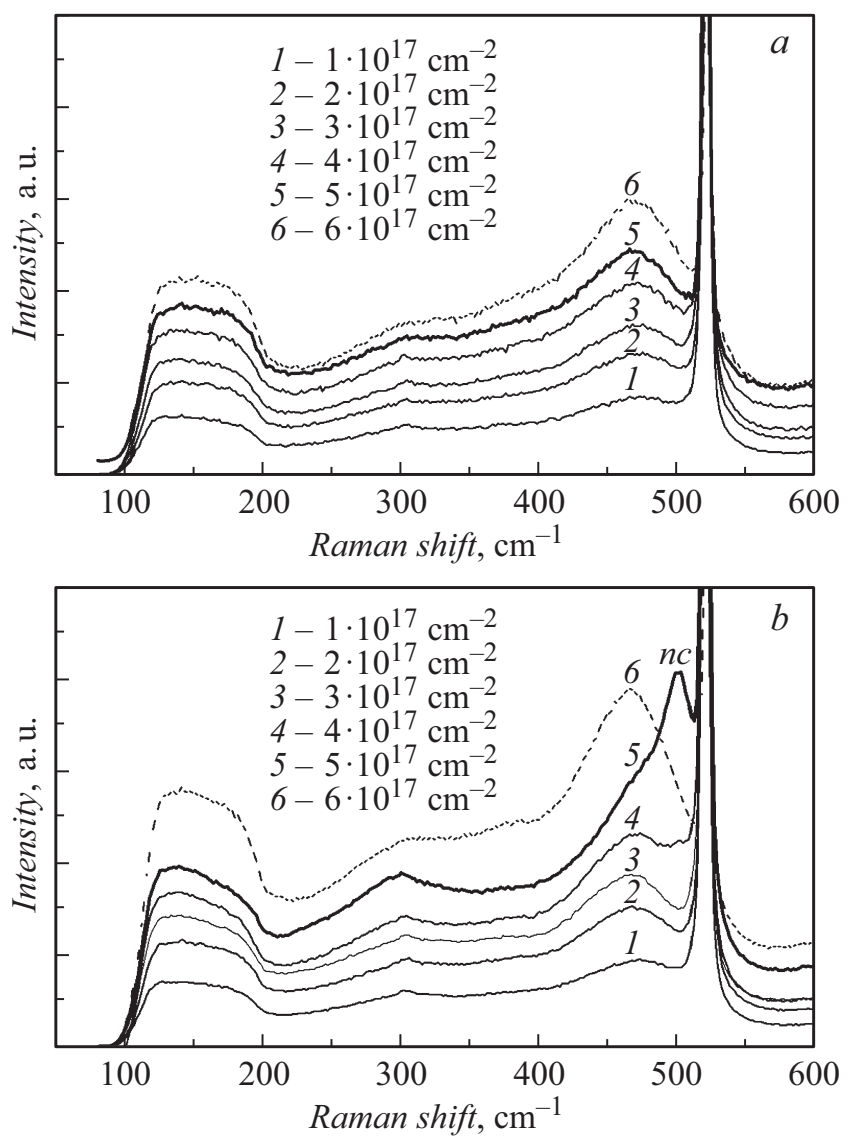

Рис. 3. Спектры КРС кремния после имплантации ионов $\mathrm{He}^{+}$с дозами от $1 \cdot 10^{17}$ до $6 \cdot 10^{17} \mathrm{~cm}^{-2}(1-6)$, возбужденные лазером с длиной волны $532 \mathrm{~nm}$ и мощностями $1(a)$ и $18 \mathrm{~mW}(b)$.

состояния кремния является сдвиг ТО-моды кристаллического кремния в низкочастотную область спектра, что может быть обусловлено двумя эффектами: пленением фононных мод (the phonon confinement) или тепловым нагревом нанокристаллов, вызванным большой мощностью лазера. Формирование нанокристаллов кремния с размерами $10-20 \mathrm{~nm}$ про-

Письма в ЖТФ, 2018, том 44, вып. 7 
исходило при имплантировании ионов гелия с дозами $(4-5) \cdot 10^{17} \mathrm{~cm}^{-2}$ и лазерном нагреве с мощностью $18 \mathrm{~mW}$ (температура в лазерном пятне составляла $\sim 800 \mathrm{~K}[5])$. Это сопровождалось появлением линии $502 \mathrm{~cm}^{-1}$ в спектре 4 (рис. $3, b$ ) и резким увеличением ее интенсивности в спектре 5 (пик $n c$ на рис. $3, b$ ). В случае пленения фононных мод, обусловленного малыми размерами нанокристаллов (менее $10 \mathrm{~nm}$ ), сдвиг составлял бы несколько обратных сантиметров и маскировался бы сильной линией кристаллического кремния (спектр 6 на рис. $3, b$ ).

Таким образом, методами рентгеновской рефлектометрии, просвечивающей электронной микроскопии и комбинационного рассеяния света впервые показано, что нанокристаллы кремния могут быть сформированы в процессе образования гелиевых пузырей при плазменноиммерсионной имплантации ионов гелия в кремниевую подложку. Установлено, что нанокристаллы образуются в узком диапазоне доз ионов гелия от $4 \cdot 10^{17}$ до $5 \cdot 10^{17} \mathrm{~cm}^{-2}$ при энергии $5 \mathrm{keV}$. Они имеют размеры 10-20 nm и расположены ниже защитного аморфного слоя. Мы полагаем, что эти результаты могут быть использованы при формировании кремниевых наноструктур в планарной технологии.

Работа выполнена в рамках Государственного задания ФАНО России. Часть работы (КРС) осуществлена при использовании оборудования ЦКП ФГБНУ ТИСНУМ при поддержке Министерства образования и науки РФ в рамках выполнения соглашения № 14.593.21.0007 от 28.08.2017 г., уникальный идентификатор соглашения RFMEFI59317X0007.

\section{Список литературы}

[1] Mangolini L. // J. Vac. Sci. Technol. B. 2013. V. 31. N 2. P. 020801 (1-29).

[2] Priolo F., Gregorkiewicz T., Galli M., Krauss T.F. // Nature Nanotechnol. 2014. V. 9. P. 19-32.

[3] Sun C., Wade M.T., Lee Y., Orcutt J.S., Alloatti L., Georgas M.S., Waterman A.S., Shainline J.M., Avizienis R.R., Lin S., Moss B.R., Kumar R., Pavanello F., Atabaki A.H., Cook H.M., Ou A.J., Leu J.C., Chen Y.-H., Asanović K., Ram R.J., Popovic M.A., Stojanovic V.M. // Nature. 2015. V. 528. P. 534-538.

[4] Korotchenkov G., Cho B.K. // Critical Rev. Solid State Mater. Sci. 2010. V. 35. N 3. P. $153-260$.

[5] Lihao H., Zeman M., Smets A.H.M. // Nanoscale. 2015. V. 7. N 18. P. 83898397.

Письма в ЖТФ, 2018, том 44, вып. 7 
[6] Турищев С.Ю., Терехов В.А., Коюда Д.А., Панков К.Н., Ершов А.В., Грачев Д.А., Машин А.И., Домашевская Э.П. // ФТП. 2013. Т. 47. В. 10. C. $1327-1334$.

[7] Griffoen C.C., Evans J.H., de Jong P.C., van Veen A. // Nucl. Instrum. Meth. Phys. Res. B. 1987. V. 27. N 3. P. 417-420.

[8] Siegele R., Weatherly G.C., Haugen H.K., Lockwood D.J., Howe L.M. // Appl. Phys. Lett. 1995. V. 66. N 11. P. 1319-1321.

[9] Мяконьких А.В., Рогожин А.Е., Руденко К.В., Лукичев В.Ф. // Микроэлектроника. 2013. Т. 42. № 4. С. 306-313.

[10] Lomov A., Shcherbachev K., Chesnokov Yu., Kiselev D. // J. Appl. Cryst. 2017. V. 50. Pt. 2. P. 539-546. 